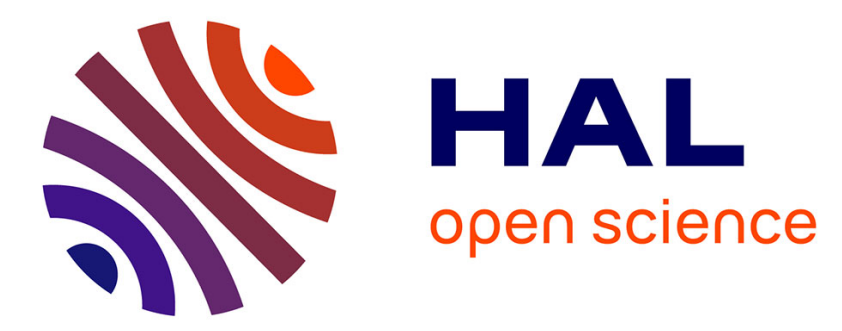

\title{
MAGNETIZED PLASMA PARAMETRIC RESONANCE IN NON-MONOCHROMATIC PUMP-WAVE
}

Yu. Aliev, O. Gradov, Vivien Stefan

\section{> To cite this version:}

Yu. Aliev, O. Gradov, Vivien Stefan. MAGNETIZED PLASMA PARAMETRIC RESONANCE IN NON-MONOCHROMATIC PUMP-WAVE. Journal de Physique Colloques, 1979, 40 (C7), pp.C7557-C7-558. 10.1051/jphyscol:19797269 . jpa-00219255

HAL Id: jpa-00219255

https://hal.science/jpa-00219255

Submitted on 1 Jan 1979

HAL is a multi-disciplinary open access archive for the deposit and dissemination of scientific research documents, whether they are published or not. The documents may come from teaching and research institutions in France or abroad, or from public or private research centers.
L'archive ouverte pluridisciplinaire HAL, est destinée au dépôt et à la diffusion de documents scientifiques de niveau recherche, publiés ou non, émanant des établissements d'enseignement et de recherche français ou étrangers, des laboratoires publics ou privés. 


\section{MAGNETIZED PLASMA PARAMETRIC RESONANCE IN NON-MONOCHROMATIC PUMP-WAVE}

Yu. M. Aliev, O.M. Gradov and V. Stefan ${ }^{*}$.

P.N. Lebedev Physical Institute, Academy of Sciences of the U.S.S.R., Moscow, U.S.S.R. *oris Kidric Institute of Nuclear Sciences - Vinca, Beograd, Yugoslavia.

Parametric effects of monochromatic pump-wave interacting with plasma, in present time, are well studied $/ 1 /$. On the other hand in all actual experiments dealing with an interaction of the radio or laser radiation with plasma we have signals duration of which is finite in time. Some aspects of the theory of parametric resonance in non-monochromatic pump-wave for non-magnetized plasma are given in $12-4 /$. In this work we represent some aspects of the finite-bandwidth parametric theory for magnetized plasma. It has been shown that the effect of finite-bandwidth leads to stabilization or facilitation of parametric growth of the turbulent notse. We consider infinite, homogeneous, fully 1onized, magnetized plasma interacting with the pump fleld

$$
E(t)=E_{0}(t) \sin \left(\omega_{0} r+\phi(t)\right)
$$

where the amplitude and phase are assumed to be slow varying compared with carrier frequency $\omega_{0}$, which is chosen so to be near to the eigen-frequencies of high-frequency $\left(w_{h} \gg b_{T e}\right)$ magnetized plasma oscillations. We also consider a set of rectangular impulses with duration $\boldsymbol{C}$, repetition period $T$ and peak intensity $E_{0^{-}}$Note, that the conclusions presented below are valid for cases of any shape of $E_{o}(t)$ and $\phi(t)$ except the demand for the periodicity of $E_{0}(t)$ and $\phi(t)$ with the period $T$ that must be satisfied.

Let us consider the amplitude-modulated $\left(\phi(t)=\phi_{0}\right)$ pump wave with frequency $\omega_{0}$ so that $\omega_{0}-\omega_{c e} \gg S 2$ is valid in the case when the oscillation velocity of electrons is 'significantly less than the thermal velocity $V_{T e}$. In the case when the frequency of the pulse repetition $52=2 a / T$ is much higher than all low eigen-frequencies of the magnetized plasma oscillation $\left(\Omega\left(\gg \omega_{5}\right)\right.$ in the case of periodical $(\Delta>0)$ and aperiodical $\left(\Delta<0, \Delta=w_{\sigma} \omega_{k}(\vec{b})\right.$ instability the following expression for the threshold is obtained

$$
\frac{E_{n H R}^{2}}{4 \pi n_{e} T_{e}}=\frac{T^{2}}{\tau^{2}} \Lambda, \Lambda=\frac{E_{T M R, M O N}^{2}}{4 \bar{u} n_{e} T_{e}}
$$

Here, $E_{\text {THR, MON }}$ is the threshold for the ca se of monochromatic pump-wave. From (2) it is evident that the existence of the discrete external pump-wave leads to the stabilization of plasma - the increasing of the threshold $\frac{T}{\tau}$ times is apparent. Note that the wave numbers of exclted oscillations are the same as in the case of rionochromatic pump-wave.

With decreasing of the pulse repetition frequency the possibility for resonance $\Delta^{2} \sim n^{2} \Omega^{2}$ can be encountered which lead, in both periodical and aperiodical case, to the ion-sound instabilities. In this case the following expression for the threshold is obtained.

$\frac{\left(\left|B_{n}\right|^{2}+\left|B_{n}^{+}\right|^{2}\right)_{T+R}}{k^{2} V_{D e}^{2}}=\frac{1}{2} \Lambda$

Here:

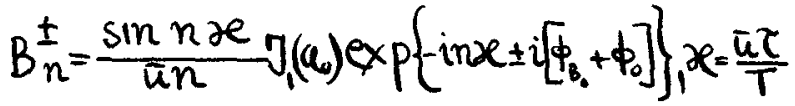

$a_{0}=a_{B}(0 \leq t \leq \tau) ; \phi_{B O}=\phi_{B}(0 \leq t \leq \tau)$

The remaining notations are conventional. The wave numbers of excited oscillations are defined from $\Delta \pm n Q= \pm \omega$, in the decay case $\left(\pi \ll w_{S}\right)$ or $\Delta \pm n \Omega= \pm \pi / \sqrt{3}$ in the nondecay case $\left(\tilde{j} \gg \omega_{s}\right)$. The minimum thres hold value from (3) is reached if $n=1$ and $2 \tau=T$. In the meantime for the positive mismatching $(\Delta>0)$ the threshold va lue (3) is higher than the value obtained by (2). It means that in the domain considered $\leadsto W_{S}$ for $\Delta>0$ the treshold value is defined by (2) and the wave number of oscillations satisfies $\Delta=\omega_{S}$ in the decay $\operatorname{case}\left(\omega_{s} \gg \pi\right)$ or $\Delta=\pi / \sqrt{3}$ in the nondecay 
$\left(w_{s} \ll \tilde{y}\right)$ case. In the same time for the negative mismatching $(\Delta<0)$ the resonances $\Delta=-n \Omega$ make possible excitations of ion-sound oscillations with the threshold value given by (3) which appears to be less than the corresponding value in the case of aperiodical instabilities $\Delta=-\bar{y}^{2}$.

With further decrease in the pulse repetition frequency a situation when $n \Omega \sim 2 \omega_{S}$ can be reached ( $n$-odd number). In the nondecay case when $\widetilde{\gamma} \gg \omega_{S}$ is satisfied an excitation of two ion-sound modes can take place, with the threshold and increment, respectively.

$$
\frac{E_{T H R}^{2}}{4 \bar{u} R_{R} T_{e}}=\frac{4 \tilde{\gamma} \gamma_{s}}{\omega_{h} \omega_{s}} \frac{1}{(\bar{\omega}-x) \sin x}
$$

$$
y=\frac{\omega_{s} \omega_{h}}{4 \tilde{r} k^{2} \eta_{D_{e}}^{2}}\left|\sum_{m=-\infty}^{\infty} B_{m}^{+} B_{m n}^{-}\right|-\mu_{s}
$$

\section{REFERENCES}

/1/ V.P.Silin, "Parametric Effects of High Power Radiation on Plasma", Nauka, Moscow, 1973, Chapter 3

/2/ V.V.Pustovalov, V.P.Silin, A.A.Chernikov, Ouantum Electronics (1978), S, 9

/3/ Yu.M.Aliev, O.M.Gradov, D.Sünder, Beiträge aus der Plasma Physik, B.17, H. 6 (1977) 353

/4/ Yu.M.Aliev, A.A.Chernikov, O.M.Gradov, V.V.Pustovalov, V.P.Silin, V.stefan, Eight European Conference on Controlled Fusion and Plasma Physics, contributed papers, v.l (1977) 146 , Prague
From the expression (4) it is evident that the threshold value of the nondecay instabilities is significantly less than the corresponding value in the case of monochromatic pump-wave. The optimum value for the pulse duration, in presence of which the threshold value (4) reaches minimum, is defined from

$$
\operatorname{tg} x_{0}=\bar{u}-x_{0}, x_{0}=\frac{\bar{u} \tau}{T}
$$

The wave number appearing in the righthand side of (4) is fixed by $\Delta= \pm \tilde{y}$. From here it is evident that in the case of nonmonochromatic pump-wave the decay instabilities, which are absent in the case of monochromatic pump-wave, are possible if $\Delta<O$ is satisfied. 